\title{
Comparison of Fluoroquinolone Resistance Determinants in Uropathogenic Escherichia coli between 2 Time Periods of 1989 and 2010-2014 at Gangwon Province in Korea
}

\author{
Min $\operatorname{Park}^{\dagger, *}$ \\ Department of Biomedical Laboratory Science, Daekyeung University, Gyeongsan 38547, Korea
}

\begin{abstract}
Fluoroquinolone (FQ) resistant uropathogenic Escherichia coli (UPEC) have become a major problem in urinary tract infections (UTIs). The purpose of this study was to compare the quinolone resistance-determining region (QRDR) and plasmid mediated quinolone resistance (PMQR) determinants of FQ resistant UPEC between 1989 and 2010-2014. A total of 681 strains of UPEC clinical isolates was collected from Korean healthcare facility in 1989 (123 strains) and in 2010-2014 (558 strains). The minimum inhibitory concentrations (MICs) of FQs were determined by agar dilution method. QRDRs (gyrA, gyr B, parC and parE) and PMQR determinants ( $q n r \mathrm{~A}, q n r \mathrm{~B}, q n r \mathrm{~S}, a a c\left(6^{\prime}\right)-I b-c r$ and $\left.q e p \mathrm{~A}\right)$ were analyzed polymerase chain reaction and sequencing method. Among 681 isolates, FQ resistant UPEC were 3 strains (2.4\%) in 1989 isolates and 220 strains (39.4\%) in 2010-2014 isolates. The rate of the FQ resistant UPEC strains in 2010-2014 isolates was increased than that of in 1989 isolates. UPEC isolates from 1989 and 2010-2014 were shown to carry mutations in gyrA (Ser83 and Asp87), gyrB (Ser464 and Thr469), parC (Ser80 and Glu84) and parE (Glu460, Ser458, Ile464 and Leu445). The most common mutations of QRDRs in 1989 isolates were Ser83Leu and Asp87Gly in gyrA and Ser80Ile in parC (2 strains: 66.7\%) while those in 2010-2014 isolates were Ser83Leu and Asp87Asn in gyrA and Ser80I12 and Glu84Val in parC (88 strains: 40.0\%). PMQR determinants were detected only in 2010-2014 UPEC strains (47 strains: $21.4 \%$ ).
\end{abstract}

Key Words: Uropathogenic Escherichia coli (UPEC), Quinolone-determining regions (QRDRs), Plasmid-mediated quinolone resistance determinants (PMQRs)

요로감염(urinary tract infections)은 세균성 감염질환 중 가장 흔한 것 중 하나로, 약 70 90\%는 대장균(Escherichia coli)에 의해서 발생하며 특히 남성보다 여성에서 흔히 발 생하는 것으로 알려졌다(Li et al., 2010). 세균성 요로감염 의 치료에는 fluoroquinolone계 항생제인 ciprofloxacin이 1 차 약제로 많이 사용되고 있으며(Lee et al., 2003), 그에 따라 ciprofloxacin에 대한 내성률도 꾸준히 증가하고 있다 (Chang et al., 2008). Fluoroquinolone은 세균의 DNA 복제 에 필수적으로 작용하는 DNA gyrase와 DNA topoisomerase
$\mathrm{IV}$ 를 억제함에 따라 항균효과를 나타내는 것으로 알려져 있다(Takahashi et al., 2009). DNA gyrase는 GyrA와 GyrB 로, DNA topoisomerase IV는 ParC와 ParE로 각각 2개의 subunit으로 구성되어 있다(Sung, 2018). Fluoroquinolone계 항생제에 내성을 나타내는 기전은 DNA gyrase와 DNA topoisomerase $\mathrm{IV}$ 를 암호화하는 $g y r \mathrm{~A}, g y r \mathrm{~B}, \operatorname{par} \mathrm{C}$ 및 $\operatorname{par} \mathrm{E}$ 의 소위 quinolone resistance determining region (QRDR)으 로 알려진 부위의 염기에 점돌연변이가 생기면 아미노산 이 치환되어 내성을 나타내는 것으로 알려져 있다(Yang

Received: June 16, 2020 / Revised: June 24, 2020 / Accepted: June 25, 2020

* Professor.

${ }^{\dagger}$ Corresponding author: Min Park. Department of Biomedical Laboratory Science, Daekyeung University, Gyeongsan 38547, Korea. Tel: +82-53-850-1271, Fax: +82-53-850-1496, e-mail: pm@tk.ac.kr (C) The Korean Society for Biomedical Laboratory Sciences. All rights reserved.

(c) This is an Open Access article distributed under the terms of the Creative Commons Attribution Non-Commercial License (http://creativecommons.org/licenses/by-nc/3.0/) which permits unrestricted non-commercial use, distribution, and reproduction in any medium, provided the original work is properly cited. 
Table 1. Distribution of mutation type and amino acid substitution in FQs-resistant UPEC

\begin{tabular}{|c|c|c|c|c|}
\hline \multirow{2}{*}{ Target gene } & \multirow{2}{*}{ Mutation } & \multirow{2}{*}{$\begin{array}{l}\text { Amino acid } \\
\text { substitution }\end{array}$} & $1989(n=3)$ & $2010-2014(n=220)$ \\
\hline & & & No. of isolates $(\%)$ & No. of isolates $(\%)$ \\
\hline \multirow{5}{*}{ gyrA } & $\mathrm{T} \underline{\mathbf{C G}} \rightarrow \mathrm{T} \underline{\mathbf{T} G}$ & Ser 83 to Leu & $3(100 \%)$ & $218(99.1 \%)$ \\
\hline & $\underline{\mathbf{T C G}} \rightarrow \underline{\mathbf{G C G}}$ & Ser 83 to Ala & $0(0.0 \%)$ & $1(0.5 \%)$ \\
\hline & $\mathrm{G} \underline{\mathrm{AC}} \rightarrow \mathrm{G} \underline{\mathrm{GC}}$ & Asp 87 to Gly & $3(100 \%)$ & $1(0.5 \%)$ \\
\hline & $\underline{\mathbf{G}} \mathrm{AC} \rightarrow \underline{\mathbf{T}} \mathrm{AC}$ & Asp 87 to Tyr & $0(0.0 \%)$ & $11(5.0 \%)$ \\
\hline & $\underline{\mathbf{G}} \mathrm{AC} \rightarrow \underline{\mathbf{A}} \mathrm{AC}$ & Asp 87 to Asn & $0(0.0 \%)$ & $206(93.6 \%)$ \\
\hline \multirow{2}{*}{ gyrB } & $\mathrm{T} \underline{\mathrm{C} T} \rightarrow \mathrm{T} \underline{\mathrm{TT}}$ & Ser 464 to Phe & $0(0.0 \%)$ & $3(1.4 \%)$ \\
\hline & $\mathrm{A} \underline{\mathrm{C} G} \rightarrow \mathrm{A} \underline{\mathbf{T}} \mathrm{G}$ & Thr 469 to Met & $0(0.0 \%)$ & $1(0.5 \%)$ \\
\hline \multirow{3}{*}{ parC } & $\mathrm{A} \underline{\mathbf{G}} \mathrm{C} \rightarrow \mathrm{A} \underline{\mathbf{T T}}$ & Ser 80 to Ile & $3(100 \%)$ & $220(100 \%)$ \\
\hline & GㅁA $\rightarrow$ G $\underline{\mathbf{T}} \mathrm{A}$ & Glu 84 to Val & $0(0.0 \%)$ & $91(41.4 \%)$ \\
\hline & 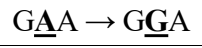 & Glu 84 to Gly & $0(0.0 \%)$ & $10(4.5 \%)$ \\
\hline \multirow{7}{*}{ parE } & $\mathrm{C} \underline{\mathbf{T T}} \rightarrow \mathrm{C} \underline{\mathrm{A}} \mathrm{T}$ & Leu 445 to His & $0(0.0 \%)$ & $1(0.5 \%)$ \\
\hline & $\underline{\mathbf{T C G}} \rightarrow \underline{\mathbf{G C G}}$ & Ser 458 to Ala & $0(0.0 \%)$ & $36(16.4 \%)$ \\
\hline & $\mathrm{T} \underline{\mathbf{C G}} \rightarrow$ T $\underline{G G}$ & Ser 458 to Trp & $0(0.0 \%)$ & $2(0.9)$ \\
\hline & $\underline{\mathbf{T C G}} \rightarrow \underline{\mathbf{A C C}}$ & Ser 458 to Thr & $0(0.0 \%)$ & $2(0.9)$ \\
\hline & 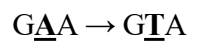 & Glu 460 to Val & $0(0.0 \%)$ & $1(0.2 \%)$ \\
\hline & $\underline{\mathbf{G}} \mathrm{AA} \rightarrow \underline{\mathbf{A}} \mathrm{AA}$ & Glu 460 to Lys & $1(33.3 \%)$ & $0(0.0 \%)$ \\
\hline & $\underline{\mathbf{A}} \mathrm{TT} \rightarrow \underline{\mathbf{T T T}}$ & Ile 464 to Phe & $0(0.0 \%)$ & $3(1.4 \%)$ \\
\hline
\end{tabular}

et al., 2017). 또 다른 내성 기전으로는 quinolone 내성 유 전자를 plasmid DNA를 통해 획득하는 plasmid-mediated quinolone resistance $(\mathrm{PMQR})$ determinants로, fluoroquinolone 계 항생제가 세균에 결합하는 것을 방해하는 $\mathrm{Qnr}(\mathrm{QnrA}$, QnrB and QnrS), aminoglycoside acetyltransferase인 AAC(6')$\mathrm{Ib}$-cr 및 quinolone efflux pump인 QepA 등이 알려져 있다 (Song et al., 2009).

본 연구에서는 강원도 소재 한 대학병원에서 1989년 에 분리한 123 주의 요로병원성 대장균(uropathogenic $E$. coli, UPEC)과 2010년부터 2014년도까지 분리된 558주의 $\mathrm{UPEC}$ 를 대상으로 quinolone계 항생제인 nalidixic acid와 fluoroquinolone계 항생제인 ciprofloxacin 및 levofloxacin에 대한 내성률 및 그 내성 기전을 비교 분석해보고자 하였 다. 1989년 3월부터 12월까지 123명의 요로감염 환자의 소 변검체에서 분리한 UPEC 123주와 2010년 7월부터 2014년 7 월까지 558 명의 요로감염 환자의 소변검체에서 분리한 UPEC 558주를 대상으로 ciprofloxacin 내성 UPEC를 선별 하여 본 연구에 사용하였다. Clinical Laboratory Standard Institute (CLSI) guideline의 기준(Patel et al., 2016)에 따라 디 스크 확산법을 수행하여 ciprofloxacin 내성 균주를 선별하 였고, 선별된 균주를 대상으로 우무 배지 희석법을 수행
하여 nalidixic acid, ciprofloxacin 및 levofloxacin에 대한 최소 억제 농도(minimum inhibitory concentration, $\mathrm{MIC}$ )를 도출하였다. 1989 년도에 분리된 $\mathrm{UPEC}$ 의 경우 123 주 중 ciprofloxacin에 내성인 균주는 3주(2.4\%)였던 반면 2010년 도부터 2014년도에 분리된 UPEC의 ciprofloxacin 내성률 은 220주(39.4\%)로 확인되었다. 비슷한 시기인 2015년 국 내 UPEC의 병원성인자와 항생제 내성률에 대한 연구에 서는 UPEC의 ciprofloxacin에 대한 내성률이 $31 \%$ 라고 보 고(Lee et al., 2015)한 결과와 다소 차이가 있었으나, 2017년 국내 항생제 내성률에 관한 연구에서는 대장균의 ciprofloxacin에 대한 내성률이 35.8\%라고 보고(Liu et al., 2019) 한 결과와 비슷하였다.

QRDRs의 아미노산 치환을 확인하기 위해 ciprofloxacin 에 내성을 나타내는 $\mathrm{UPEC}$ 의 $g y r \mathrm{~A}, \operatorname{gyr} \mathrm{B}, \operatorname{parC}$ 및 $p a r \mathrm{E}$ 유전자를 Liu 등의 방법에 따라(Liu et al., 2012) polymerase chain reaction (PCR)을 실시하고 증폭산물의 염기서열 및 아미노산 치환을 분석한 결과는 Table 1 과 같다. gyrA 유 전자 돌연변이는 83번째 Serine (Ser)이 Alanine (Ala)이나 Leucine (Leu)으로, 87번째 aspartic acid (Asp)가 Glycine (Gly), Tyrosine (Tyr) 또는 Asparagine (Asn)으로 치환되었으 며, $g y r \mathrm{~B}$ 유전자의 돌연변이는 1989년도 분리주에서는 확 
인되지 않은 반면, 2010-2014 분리주에서 464번째 Serine (Ser)이 Phenylalanine (Phe)로, 469번째 Thereonine (Thr)이 Methionine (Met)로 치환됨이 확인되었다. parC 유전자의 돌연변이는 80 번째 Serine이 Isoleucine (Ile)로, 84번째 Glutamic acid (Glu)가 Valine (Val) 및 Glycine (Gly)로 치환되었 고, $p a r \mathrm{E}$ 유전자의 돌연변이가 가장 다양한 형태로 나타 났는데, 445번째 Leucine (Leu)이 Histidine (His)으로, 458번 째 Serine이 Alanine (Ala), Tryptophan (Trp) 및 Threonine (Thr)으로, 460번째 Glutamic acid가 Valine 및 Lysine (Lsy) 으로, 464번째 Isoleucine이 Phenylalanine (Phe)으로 치환 되었음이 확인되었다. 우무 배지 희석법을 이용해 $\mathrm{MIC}$ 를 도출한 결과 1989 분리주 및 2010-2014 분리주 모두 nalidixic acid에 대해 $>128 \mu \mathrm{g} / \mathrm{mL}$ 의 결과를 나타내었으 며, ciprofloxacin과 levofloxacin에 대해서는 $4 \mu \mathrm{g} / \mathrm{mL}$ 부터 $>128 \mu \mathrm{g} / \mathrm{mL}$ 까지 다양한 $\mathrm{MIC}$ 를 확인할 수 있었다. 각 균 주별 $\mathrm{QRDRs}$ 에 아미노산이 치환된 결과를 살펴보면(Table 2), 1989 분리주의 경우 GyrA (Ser83Leu and Asp87Gly)와 ParC (Ser80Ile) 또는 ParE (Glu460Lys)에 동시에 아미노산 치환이 확인되었는데, 1996년에 보고된 Vila 등의 연구 결 과(GyrA: Ser83Leu, ParC: Ser80Ile)와 비슷하였다(Vila et al., 1996). 2010-2014 분리주의 경우에는 GyrA 아미노산 치환 이 없는 1 주를 제외한 모든 균주에서 $\mathrm{GyrA}$ 와 $\mathrm{ParC}$ 의 아 미노산 치환이 확인되었는데, GyrA (Ser83Leu, Asp87Asn) 와 $\mathrm{ParC}$ (Ser80Ile, Glu84Val)에서 동시에 4개의 아미노 산 치환이 나타난 경우가 $40 \%$ 로 가장 높았으며, GyrA (Ser83Leu, Asp87Asn)와 ParC (Ser80Ile)에서 동시에 3개의 아미노산 치환이 나타난 균주가 $31.8 \%$ 로, 두 번째로 높게 확인이 되었다. 이는 $\mathrm{GyrA}$ 와 $\mathrm{ParC}$ 에서 아미노산 치환이 가장 빈번하게 관찰되었다고 보고한 다른 연구들의 결과 와 비슷하였다(Dehbanipour et al., 2019; Sung, 2018; Betitra et al., 2014). 또한, 대장균에서는 거의 관찰되지 않는 $\mathrm{GyrB}$ 의 아미노산 치환(Ser464Phe 및 Thr469Met)이 본 연구에 서 확인되었다. 주목할 만한 점은 $g y r \mathrm{~B}$ 및 $g y r \mathrm{E}$ 의 돌연변 이에 의한 아미노산 치환은 fluoroquinolone에 대한 낮은 수준의 내성을 나타낸다고 알려져 있는데(Rehman et al., 2019), GyrA (Ser83Leu, Asp87Asn), GyrB (Ser464Phe) 그리 고 $\mathrm{ParC}$ (Ser80I12, Glu84Val)에 아미노산 치환을 나타낸 2주에서 nalidixic acid, ciprofloxacin 및 levofloxacin에 모두 고도의 내성 $(\geq 128 \mu \mathrm{g} / \mathrm{mL})$ 을 나타내는 것이 확인되었고, GyrA (Ser83Leu), GyrB (Thr469Met), ParC (Ser80Ile) 및 ParE (Ser458Ala)에 아미노산 치환을 나타낸 1주에서도 또한 fluoroquinolone계 항생제에 고도의 내성 $(>128 \mu \mathrm{g} / \mathrm{mL})$ 을 나
타내는 것으로 보아, $\mathrm{GyrA}$ 와 $\mathrm{ParC}$ 의 아미노산 치환과 더 불어 GyrB의 464번째 Serine의 Phenylalanine으로의 아미 노산 치환 또는 469번째 Threonine의 Methionine으로의 아 미노산 치환이 동반되는 경우 fluoroquinolone에 고도 내 성을 나타낼 가능성이 있을 것으로 사료된다. 2019년에 발표된 Nakano 등의 Proteus mirabilis 임상분리주를 대 상으로 한 fluoroquinolone 내성 기전 연구에 관한 논문 에서는 P. mirabilis 임상분리주 중 GyrA (Ser83Ile, Glu87Gly), GyrB (Ser464Phe) 및 ParC (Ser80Ile)로 치환된 경 우 ciprofloxacin에 대한 MIC가 $512 \mu \mathrm{g} / \mathrm{mL}$, levofloxacin에 대한 $\mathrm{MIC}$ 가 $>512 \mu \mathrm{g} / \mathrm{mL}$ 으로 나타난 결과를 보고하였는 데(Nakano et al., 2019), 본 연구에서의 결과와 비슷하였다.

Cattoir 등의 방법으로 $\mathrm{PMQR}$ determinants를 확인해 본 결과(Cattoir et al., 2007; Fihman et al., 2008; Le et al., 2009), 1989 분리주에서는 PMQR determinants가 확인되지 않은 반면, 2010-2014 분리주 220주 중 47주(21.4\%)에서 PMQR determinants가 확인되었다. PMQR determinants의 보유율은 $a a c\left(6^{\prime}\right)-I b-c r$ 유전자가 $19.1 \%$ 로 가장 높은 빈도를 보였으 며, $q n r \mathrm{~B}, q e p \mathrm{~A}, q n r \mathrm{~A}$ 가 각각 $2.3 \%, 1.4 \%, 0.5 \%$ 로 확인되었 다. 본 연구에서는 fluoroquinolone계열 항생제에 내성을 나타내는 균주 중 $\mathrm{PMQR}$ determinants만을 단독으로 보유 한 경우는 없었으며, PMQR determinants를 보유한 모든 균주에서 QRDRs의 아미노산 치환이 함께 확인되었다. 2018년 임상검체와 가축으로부터 분리된 대장균의 quinolone 내성 인자를 분석한 연구에서 대장균의 quinolone 계 항생제에 대한 내성은 plasmid DNA를 통한 PMQR determinants인 유전자의 획득 보다는 QRDRs 특히 gyrA 및 $\operatorname{parC}$ 유전자에 돌연변이 발생에 의해 나타난다고 하 였다(Sung, 2018). 하지만, Machuca 등은 $a a c\left(6^{\prime}\right)-I b-c r$ 유전 자만을 보유하고 있는 경우 ciprofloxacin에 대한 $\mathrm{MIC}$ 가 약간 증가(4 8 fold)한다고 보고하였는데(Machuca et al., 2016), 본 연구의 결과에서도(Table 3) QRDRs에 아미노산 치환과 $a a c\left(6^{\prime}\right)-I b-c r$ 유전자를 동시에 보유하고 있는 경 우(42주, 19.1\%), ciprofloxacin에 대해 높은 수준의 내성을 나타내는 것이 확인 $(32 \mu \mathrm{g} / \mathrm{mL}$ to $>128 \mu \mathrm{g} / \mathrm{mL})$ 되었다. 같은 지역에서 분리시기만이 다른 $\mathrm{UPEC}$ 를 대상으로 조사한 점으로 미루어 보았을 때, UPEC 간 PMQR determinants의 확산이 꾸준히 이루어진 것으로 생각되며, $\mathrm{PMQR}$ determinants의 확산에 따른 fluoroquinolone계 항생제에 대한 $\mathrm{MIC}$ 의 상승은 fluoroquinolone 내성 UPEC 감염의 치료에 어려움을 줄 수 있을 것으로 사료된다.

2018년 질병관리본부에서 발표된 "요로감염 항생제 사 
Table 2. Distribution of MIC of fluoroquinolones and amino acid substitutions in FQs-resistant UPEC

\begin{tabular}{|c|c|c|c|c|c|c|c|c|}
\hline \multicolumn{3}{|c|}{$\mathrm{MIC}(\mu \mathrm{g} / \mathrm{mL})$} & \multicolumn{4}{|c|}{ Amino acid substitutions } & \multirow{2}{*}{$\begin{array}{c}\begin{array}{c}1989 \\
(\mathrm{n}=3)\end{array} \\
\begin{array}{c}\text { No. of } \\
\text { isolates }(\%)\end{array}\end{array}$} & \multirow{2}{*}{$\begin{array}{c}\begin{array}{c}2010-2014 \\
(\mathrm{n}=220)\end{array} \\
\begin{array}{c}\text { No. of } \\
\text { isolates }(\%)\end{array}\end{array}$} \\
\hline NAL & CIP & LVX & GyrA & GyrB & ParC & ParE & & \\
\hline$>128$ & 4 to 128 & 4 to 64 & $\begin{array}{l}\text { Ser83Leu, } \\
\text { Asp87Asn }\end{array}$ & Wild type & Ser80Ile & Wild type & $0(0.0 \%)$ & $70(31.8 \%)$ \\
\hline$>128$ & 8 to $>128$ & 8 to 128 & $\begin{array}{l}\text { Ser83Leu, } \\
\text { Asp87Asn }\end{array}$ & Wild type & $\begin{array}{l}\text { Ser80Ile, } \\
\text { Glu84Val }\end{array}$ & Wild type & $0(0.0 \%)$ & $88(40.0 \%)$ \\
\hline$>128$ & 16 to $>128$ & 4 to $>128$ & $\begin{array}{l}\text { Ser83Leu, } \\
\text { Asp87Asn }\end{array}$ & Wild type & Ser80Ile & Ser458Ala & $0(0.0 \%)$ & $27(12.3 \%)$ \\
\hline$>128$ & 32 to $>128$ & 16 to 64 & $\begin{array}{l}\text { Ser83Leu, } \\
\text { Asp87Asn }\end{array}$ & Wild type & $\begin{array}{l}\text { Ser80Ile, } \\
\text { Glu84Gly }\end{array}$ & Wild type & $0(0.0 \%)$ & $9(4.1 \%)$ \\
\hline$>128$ & 32 to 64 & 16 to 32 & $\begin{array}{l}\text { Ser83Leu, } \\
\text { Asp87Tyr }\end{array}$ & Wild type & Ser80Ile & Ser458Ala & $0(0.0 \%)$ & $4(1.8 \%)$ \\
\hline$>128$ & 16 & 16 & $\begin{array}{l}\text { Ser83Leu, } \\
\text { Asp87Gly }\end{array}$ & Wild type & Ser80Ile & Wild type & $0(0.0 \%)$ & $1(0.5 \%)$ \\
\hline$>128$ & 8 & 8 & $\begin{array}{l}\text { Ser83Leu, } \\
\text { Asp87Gly }\end{array}$ & Wild type & Ser80Ile & Wild type & $2(66.7 \%)$ & $0(0.0 \%)$ \\
\hline$>128$ & 64 & 64 & $\begin{array}{l}\text { Ser83Leu, } \\
\text { Asp87Gly }\end{array}$ & Wild type & Ser80Ile & Glu460Lys & $1(33.3 \%)$ & $0(0.0 \%)$ \\
\hline$>128$ & 32 & 16 & $\begin{array}{l}\text { Ser83Leu, } \\
\text { Asp87Tyr }\end{array}$ & Wild type & Ser80Ile & Wild type & $0(0.0 \%)$ & $1(0.5 \%)$ \\
\hline$>128$ & 128 & 16 & $\begin{array}{l}\text { Ser83Ala, } \\
\text { Asp87Tyr }\end{array}$ & Wild type & Ser80Ile & Wild type & $0(0.0 \%)$ & $1(0.5 \%)$ \\
\hline$>128$ & 64 & 16 & Ser83Leu & Wild type & $\begin{array}{l}\text { Ser80Ile, } \\
\text { Glu84Val }\end{array}$ & Wild type & $0(0.0 \%)$ & $1(0.5 \%)$ \\
\hline$>128$ & 128 & 32 & $\begin{array}{l}\text { Ser83Leu, } \\
\text { Asp87Tyr }\end{array}$ & Wild type & $\begin{array}{l}\text { Ser80Ile, } \\
\text { Glu84Gly }\end{array}$ & Wild type & $0(0.0 \%)$ & $1(0.5 \%)$ \\
\hline$>128$ & 32 to 64 & 16 & $\begin{array}{l}\text { Ser83Leu, } \\
\text { Asp87Asn }\end{array}$ & Wild type & Ser80Ile & Ser458Trp & $0(0.0 \%)$ & $2(0.9 \%)$ \\
\hline$>128$ & 16 to 128 & 8 to 16 & $\begin{array}{l}\text { Ser83Leu, } \\
\text { Asp87Asn }\end{array}$ & Wild type & Ser80Ile & Ser458Thr & $0(0.0 \%)$ & $2(0.9 \%)$ \\
\hline$>128$ & 32 & 16 & Wild type & Wild type & Ser80Ile & Ser458Ala & $0(0.0 \%)$ & $1(0.5 \%)$ \\
\hline$>128$ & 32 to $>128$ & 8 to 128 & $\begin{array}{l}\text { Ser83Leu, } \\
\text { Asp87Tyr }\end{array}$ & Wild type & Ser80Ile & Ser458Ala & $0(0.0 \%)$ & $3(1.4 \%)$ \\
\hline$>128$ & 16 to 32 & 16 to 32 & $\begin{array}{l}\text { Ser83Leu, } \\
\text { Asp87Asn }\end{array}$ & Wild type & Ser80Ile & Ile464Phe & $0(0.0 \%)$ & $3(1.4 \%)$ \\
\hline$>128$ & 32 & 16 & $\begin{array}{l}\text { Ser83Leu, } \\
\text { Asp87Asn }\end{array}$ & Wild type & Ser80Ile & Glu460Val & $0(0.0 \%)$ & $1(0.5 \%)$ \\
\hline$>128$ & 32 & 16 & $\begin{array}{l}\text { Ser83Leu, } \\
\text { Asp87Asn }\end{array}$ & Wild type & Ser80Ile & Leu445His & $0(0.0 \%)$ & $1(0.5 \%)$ \\
\hline$>128$ & 64 & 64 & $\begin{array}{l}\text { Ser83Leu, } \\
\text { Asp87Asn }\end{array}$ & Ser464Phe & Ser80Ile & Wild type & $0(0.0 \%)$ & $1(0.5 \%)$ \\
\hline$>128$ & $>128$ & $\geq 128$ & $\begin{array}{l}\text { Ser83Leu, } \\
\text { Asp87Asn }\end{array}$ & Ser464Phe & $\begin{array}{l}\text { Ser80Ile, } \\
\text { Glu84Val }\end{array}$ & Wild type & $0(0.0 \%)$ & $2(0.9 \%)$ \\
\hline$>128$ & $>128$ & $>128$ & $\begin{array}{l}\text { Ser83Leu, } \\
\text { Asp87Tyr }\end{array}$ & Thr469Met & Ser80Ile & Ser458Ala & $0(0.0 \%)$ & $1(0.5 \%)$ \\
\hline
\end{tabular}

Abbreviations: NAL, nalidixic acid; LVX, levofloxacin; CIP, ciprofloxacin 
Table 3. Antibiotic resistance profiles and qionolene resistance-determining region mutations in strains with a plasmid-mediated quinolone resistance gene

\begin{tabular}{|c|c|c|c|c|c|c|c|c|c|c|c|c|}
\hline \multicolumn{3}{|c|}{$\mathrm{MIC}(\mu \mathrm{g} / \mathrm{mL})$} & \multicolumn{5}{|c|}{ PMQR genes } & \multicolumn{4}{|c|}{ QRDR } & \multirow{2}{*}{$\begin{array}{l}\text { No. of PMQR } \\
\text { positive isolates } \\
\quad(\mathrm{n}=47)\end{array}$} \\
\hline NAL & $\mathrm{CIP}$ & LVX & $q n r \mathrm{~A}$ & $q n r \mathrm{~B}$ & $q n r \mathrm{~S}$ & $\begin{array}{l}a a c\left(6^{\prime}\right)- \\
I b-c r\end{array}$ & qep $\mathrm{A}$ & GyrA & GyrB & ParC & ParE & \\
\hline$>128$ & 32 & 32 & - & + & - & - & - & $\begin{array}{l}\text { Ser83Leu, } \\
\text { Asp87Asn }\end{array}$ & Wild type & $\begin{array}{l}\text { Ser80Ile, } \\
\text { Glu84Val }\end{array}$ & Wild type & 1 \\
\hline$>128$ & 64 & 8 & - & - & - & + & - & $\begin{array}{l}\text { Ser83Leu, } \\
\text { Asp87Asn }\end{array}$ & Wild type & $\begin{array}{l}\text { Ser80Ile, } \\
\text { Glu84Val }\end{array}$ & Wild type & 4 \\
\hline$>128$ & 64 & 16 & - & - & - & + & - & $\begin{array}{l}\text { Ser83Leu, } \\
\text { Asp87Asn }\end{array}$ & Wild type & $\begin{array}{l}\text { Ser80Ile, } \\
\text { Glu84Val }\end{array}$ & Wild type & 3 \\
\hline$>128$ & 128 & 8 & - & - & - & + & - & $\begin{array}{l}\text { Ser83Leu, } \\
\text { Asp87Asn }\end{array}$ & Wild type & $\begin{array}{l}\text { Ser80Ile, } \\
\text { Glu84Val }\end{array}$ & Wild type & 1 \\
\hline$>128$ & 128 & 16 & - & - & - & + & - & $\begin{array}{l}\text { Ser83Leu, } \\
\text { Asp87Asn }\end{array}$ & Wild type & $\begin{array}{l}\text { Ser80Ile, } \\
\text { Glu84Val }\end{array}$ & Wild type & 9 \\
\hline$>128$ & 128 & 32 & - & - & - & + & - & $\begin{array}{l}\text { Ser83Leu, } \\
\text { Asp87Asn }\end{array}$ & Wild type & $\begin{array}{l}\text { Ser80Ile, } \\
\text { Glu84Val }\end{array}$ & Wild type & 3 \\
\hline$>128$ & $>128$ & 16 & - & - & - & + & - & $\begin{array}{l}\text { Ser83Leu, } \\
\text { Asp87Asn }\end{array}$ & Wild type & $\begin{array}{l}\text { Ser80Ile, } \\
\text { Glu84Val }\end{array}$ & Wild type & 3 \\
\hline$>128$ & $>128$ & 32 & - & - & - & + & - & $\begin{array}{l}\text { Ser83Leu, } \\
\text { Asp87Asn }\end{array}$ & Wild type & $\begin{array}{l}\text { Ser80Ile, } \\
\text { Glu84Val }\end{array}$ & Wild type & 2 \\
\hline$>128$ & $>128$ & $>128$ & - & - & - & + & - & $\begin{array}{l}\text { Ser83Leu, } \\
\text { Asp87Asn }\end{array}$ & Wild type & $\begin{array}{l}\text { Ser80Ile, } \\
\text { Glu84Val }\end{array}$ & Wild type & 1 \\
\hline$>128$ & 128 & 16 & - & - & - & + & - & $\begin{array}{l}\text { Ser83Leu, } \\
\text { Asp87Asn }\end{array}$ & Wild type & Ser80Ile & Ser458Ala & 2 \\
\hline$>128$ & 128 & 32 & - & - & - & + & - & $\begin{array}{l}\text { Ser83Leu, } \\
\text { Asp87Asn }\end{array}$ & Wild type & Ser80Ile & Ser458Ala & 3 \\
\hline$>128$ & 128 & 64 & - & - & - & + & - & $\begin{array}{l}\text { Ser83Leu, } \\
\text { Asp87Asn }\end{array}$ & Wild type & Ser80Ile & Ser458Ala & 1 \\
\hline$>128$ & $>128$ & 16 & - & - & - & + & - & $\begin{array}{l}\text { Ser83Leu, } \\
\text { Asp87Asn }\end{array}$ & Wild type & Ser80Ile & Ser458Ala & 1 \\
\hline$>128$ & $>128$ & 32 & - & + & - & + & - & $\begin{array}{l}\text { Ser83Leu, } \\
\text { Asp87Asn }\end{array}$ & Wild type & Ser80Ile & Ser458Ala & 2 \\
\hline$>128$ & $>128$ & 32 & - & - & - & + & + & $\begin{array}{l}\text { Ser83Leu, } \\
\text { Asp87Asn }\end{array}$ & Wild type & Ser80Ile & Ser458Ala & 1 \\
\hline$>128$ & $>128$ & $>128$ & + & - & - & - & - & $\begin{array}{l}\text { Ser83Leu, } \\
\text { Asp87Asn }\end{array}$ & Wild type & Ser80Ile & Ser458Ala & 1 \\
\hline$>128$ & 64 & 16 & - & - & - & + & - & Ser83Leu & Wild type & $\begin{array}{l}\text { Ser80Ile, } \\
\text { Glu84Val }\end{array}$ & Wild type & 1 \\
\hline$>128$ & 128 & 16 & - & - & - & - & + & $\begin{array}{l}\text { Ser83Ala, } \\
\text { Asp87Tyr }\end{array}$ & Wild type & Ser80Ile & Wild type & 1 \\
\hline$>128$ & 128 & 16 & - & - & - & + & - & $\begin{array}{l}\text { Ser83Leu, } \\
\text { Asp87Asn }\end{array}$ & Wild type & Ser80Ile & Ser458Thr & 1 \\
\hline$>128$ & 128 & 32 & - & + & - & + & - & $\begin{array}{l}\text { Ser83Leu, } \\
\text { Asp87Asn }\end{array}$ & Wild type & Ser80Ile & Wild type & 1 \\
\hline$>128$ & 128 & 64 & - & - & - & + & - & $\begin{array}{l}\text { Ser83Leu, } \\
\text { Asp87Asn }\end{array}$ & Wild type & Ser80Ile & Wild type & 1 \\
\hline$>128$ & $>128$ & 64 & - & - & - & - & + & $\begin{array}{l}\text { Ser83Leu, } \\
\text { Asp87Asn }\end{array}$ & Wild type & $\begin{array}{l}\text { Ser80Ile, } \\
\text { Glu84Gly }\end{array}$ & Wild type & 1 \\
\hline$>128$ & $>128$ & $\geq 128$ & - & - & - & + & - & $\begin{array}{l}\text { Ser83Leu, } \\
\text { Asp87Asn }\end{array}$ & Ser464Phe & $\begin{array}{l}\text { Ser80Ile, } \\
\text { Glu84Val }\end{array}$ & Wild type & 2 \\
\hline
\end{tabular}


Table 3. Antibiotic resistance profiles and qionolene resistance-determining region mutations in strains with a plasmid-mediated quinolone resistance gene (Continued)

\begin{tabular}{|c|c|c|c|c|c|c|c|c|c|c|c|c|}
\hline \multicolumn{3}{|c|}{ MIC $(\mu \mathrm{g} / \mathrm{mL})$} & \multicolumn{5}{|c|}{ PMQR genes } & \multicolumn{4}{|c|}{ QRDR } & \multirow{2}{*}{$\begin{array}{l}\text { No. of PMQR } \\
\text { positive isolates } \\
\quad(n=47)\end{array}$} \\
\hline NAL & $\mathrm{CIP}$ & LVX & $q n r \mathrm{~A}$ & $q n r \mathrm{~B}$ & $q n r \mathrm{~S}$ & $\begin{array}{l}a a c\left(6^{\prime}\right)- \\
I b-c r\end{array}$ & qep $\mathrm{A}$ & GyrA & GyrB & ParC & ParE & \\
\hline$>128$ & 32 & 16 & - & - & - & + & - & $\begin{array}{l}\text { Ser83Leu, } \\
\text { Asp87Tyr }\end{array}$ & Wild type & Ser80Ile & Ser458Ala & 1 \\
\hline$>128$ & 32 & 32 & - & + & - & - & - & $\begin{array}{l}\text { Ser83Leu, } \\
\text { Asp87Asn }\end{array}$ & Wild type & Ser80Ile & Ile464Phe & 1 \\
\hline
\end{tabular}

Abbreviations: NAL, nalidixic acid; LVX, levofloxacin; CIP, ciprofloxacin

용지침"에서는 미국과 유럽에서는 fluoroquinolone계 항생 제가 1 차 약제로 권고되고 있으나, 국내에서 분리되고 있 는 요로감염 원인균의 fluoroquinolone계 항생제에 대한 내성률이 높아 fluoroquinolone계 항생제 사용 시 치료 실패의 가능성이 있어 nitrofurantoin이나 pivmecillinam과 같은 대체 항생제를 사용하도록 권고하고 있다. 하지만 fluoroquinolone을 대체 할 수 있는 항생제들의 원활치 못 한 수급에 따라 아직까지도 요로감염 치료의 1 차 약제로 fluoroquinolone을 사용하는 실정이라고 하였다(Kang et al., 2018). 국내에서 분리되고 있는 대장균의 fluoroquinolone 계 항생제인 ciprofloxacin에 대한 내성률은 이미 $35 \%$ 이 상으로 보고되고 있으므로(Liu et al., 2019), fluoroquinolone 계열 항생제 내성을 나타내는 UPEC의 증가와 확산을 막 기 위해서는 fluoroquinolone 계열 항생제 특히, ciprofloxacin의 무분별한 사용을 줄이고 요로감염의 1 차 약제로 써 다른 항생제를 대체 사용하는 노력을 기울여야 할 것 으로 생각된다. 앞으로도 fluoroquinolone 계열 항생제에 내성을 나타내는 UPEC에 대한 모니터링을 지속적으로 실시한다면 확산 방지 및 치료 방향 결정에 큰 도움이 되리라 사료된다. 또한, 본 연구에서 확인된 $g y r \mathrm{~B}$ 의 돌연 변이에 따른 $\mathrm{GyrB}$ 의 아미노산 치환을 나타낸 균주의 수 가 너무 적었으므로 $\mathrm{GyrB}$ 의 아미노산 치환에 따른 fluoroquinolone 내성 기전에 대한 후속 연구가 필요하리라 생 각된다.

\section{ACKNOWLEDGEMENT}

본 연구는 정부(과학기술정보통신부)의 재원으로 한 국연구재단의 지원을 받아 수행된 연구임(No. 2019R1F1A1057035).

\section{CONFLICT OF INTEREST}

No conflict of interests exists for any of the authors.

\section{REFERENCES}

Betitra Y, Teresa V, Miguel V, Abdelaziz T. Determinants of Quinolone Resistance in Escherichia coli Causing CommunityAcquired Urinary Tract Infection in Bejaia, Algeria. Asian Pac J Trop Med. 2014. 7: 462-467.

Cattoir V, Poirel L, Rotimi V, Soussy CJ, Nordmann P. Multiplex PCR for detection of plasmid-mediated quinolonone resistance $q n r$ genes in ESBL-producing enterobacterial isolates. J Antimicrob Chemother. 2007. 60: 394-397.

Chang IH, Bang SH, Choi NY, Park SY, Han JH, Ahn SH. Trends in the Emergence of Ciprofloxacin-resistant Escherichia coli and the Relationship with Underlying Diseases in Patients with Urinary Tract Infection. Korean J Urol. 2008. 49: 66-71.

Dehbanipour D, Khanahmad H, Sedighi M, Bialvaei AZ, Faghri J. High Prevalence of Fluoroquinolone-Resistant Escherichia coli Strains Isolated From Urine Clinical Samples. J Prev Med Hyg. 2019. 29; 60: E25-E30.

Fihman V, Lartigue MF, Jacquier H, Meunier F, Schnepf N, Raskine L, Riahi J, Sanson-le Pors MJ, Berçot B. Appearance of $a a c\left(6^{\prime}\right)-I b-c r$ gene among extended-spectrum beta-lactamaseproducing Enterobacteriaceae in a French hospital. J Infect. 2008. 56: 454-459.

Kang CI, Kim JE, Park DW, Kim BN, Ha US, Lee SJ, Yeo JK, Min SK, Lee HY, Wie SH. Clinical Practice Guidelines for the Antibiotic Treatment of Community-Acquired Urinary Tract Infections. Infect Chemother. 2018. 50: 67-100.

Li D, Liu B, Guo X, Liu F, Feng L, Wang L. A multiplex PCR method to detect 14 Escherichia coli serogroups associated with urinary tract infections. J Microbiol Methods. 2010. 82: 71-77.

Liu X, Boothe DM, Thungrat K, Aly S. Mechanisms accounting for fluoroquinolone multidrug resistance Escherichia coli isolated from companion animals. Vet Microbiol. 2012. 28; 
161: $159-168$

Liu CS, Yoon EJ, Kim DK, Shin JH, Shin JH, Shin KS, Kim YA, Uh Y, Kim HS, Kim YR, Jeong SH. Antimicrobial resistance in South Korea: A report from the Korean global antimicrobial resistance surveillance system (Kor-GLASS) for 2017. J Infect Chemother. 2019. 25: 845-859.

Le TM, Baker S, Le TP, Le TP, Cao TT, Tran TT, Nguyen VM, Campbell JI, Lam MY, Nguyen TH, Nguyen VV, Farrar J, Schultsz C. High prevalence of plasmid-mediated quinolone resistance determinants in commensal members of the Enterobacteriaceae in Ho Chi Minh City, Vietnam. J Med Microbiol. 2009. 58: 1585-1592.

Lee SJ, Cho YH, Kim BW, Lee JG, Jung SI, Lee SD, Lee SE, Kim ME, Choi YD, Rim JS, Sim BS, Cho IR, Ryu SB, Kim CS, Kim WJ, Lee TY. A Multicenter Study of Antimicrobial Susceptibility of Uropathogens Causing Acute Uncomplicated Cystitis in Woman. Korean J Urol. 2003. 44: 697-701.

Lee JH, Subhadra B, Son YJ, Kim DH, Park HS, Kim JM, Koo $\mathrm{SH}$, Oh MH, Kim HJ, Choi CH. Phylogenetic group distributions, virulence factors and antimicrobial resistance properties of uropathogenic Escherichia coli strains isolated from patients with urinary tract infections in South Korea. Letters in Applied Microbiology. 2015. 62: 84-90.

Machuca J, Ortiz M, Recacha E, Díaz-De-Alba P, Docobo-Rerez F, Rodríguez-Martínez JM., Pascual A. Impact of AAC(6')-Ib-cr in combination with chromosomal-mediated mechanisms on clinical quinolone resistance in Escherichia coli. J Antimicrob Chemother. 2016. 71: 2066-3071.

Nakano R, Nakano A, Abe M, Nagano N, Ashara M, Furukawa T, Ono Y, Yano H, Okamoto R. Prevalence and mechanism of fluoroquinolone resistance in clinical isolates of Proteus mirabilis in Japan. Heliyon. 2019. 2; 5: e10291.

Patel J, Cockerill III F, Eliopoulos G, Jenkins S, Lewis II J, Limbago B, Nicolau D, Patel R, Powell M, Richter S, Swenson J, Traczewaki M, Turnidge J, Weinstein M, Zimmer B. Performance standards for antimicrobial susceptibility testing. 2016. 26th ed. pp. 52-60. Clinical Laboratory Standards Institute. Wayne, PA, USA.

Rehman A, Patrick WM., Lamont IL. Mechanisms of Ciprofloxacin Resistance in Pseudomonas aeruginosa: New Approaches to an Old Problem. J Med Microbiol. 2019. 68: 1-10.

Song SW, Lee EY, Koh EM, Ha HS, Jeong HJ, Bae IK, Jeong SH. Antibiotic resistance mechanisms of Escherichia coli isolates from urinary specimens. Korean J Lab Med. 2009. 29: 17-24.

Sung JY. Analysis of Quinolone Resistance Determinants in Escherichia coli Isolated from Clinical Specimens and Livestock Feces. Korean J Clin Lab Sci. 2018. 50: 422-430.

Takahashi A, Muratani T, Yasuda M, Takahashi S, Monden K, Ishikawa K, Kiyota H, Arakawa S, Matsumoto T, Shima H, Kurazono H, Yamamoto S. Genetic profiles of fluoroquinoloneresistant Escherichia coli isolates obtained from patients with cystitis: phylogeny, virulence factors, PAIusp subtypes, and mutation patterns. J Clin Microbiol. 2009. 47: 791-795.

Vila J, Ruiz J, Goñi P, De Anta MT. Detection of Mutations in parC in Quinolone-Resistant Clinical Isolates of Escherichia coli. Antimicrob Agents Chemother. 1996. 40: 491-493.

Yang HS, Kim YJ, Cho SY, Nam YS, Oh TS, Park KS, Kim HC, Lee HJ. Fluoroquinolone Resistance Mechanisms by Molecular Epidemiologic Study of Ciprofloxacin-Nonsusceptible Escherichia coli Sequence Types Isolated from Clinical Specimens in a Tertiary Care University Hospital in Korea: Emergence of Clone ST131, 2006-2008. Ann Clin Lab Sci. 2017 47: 511-515.

https://doi.org/10.15616/BSL.2020.26.2.120

Cite this article as: Park M. Comparison of Fluoroquinolone Resistance Determinants in Uropathogenic Escherichia coli between 2 Time Periods of 1989 and 2010-2014 at Gangwon Province in Korea. Biomedical Science Letters. 2020. 26: 120-126. 